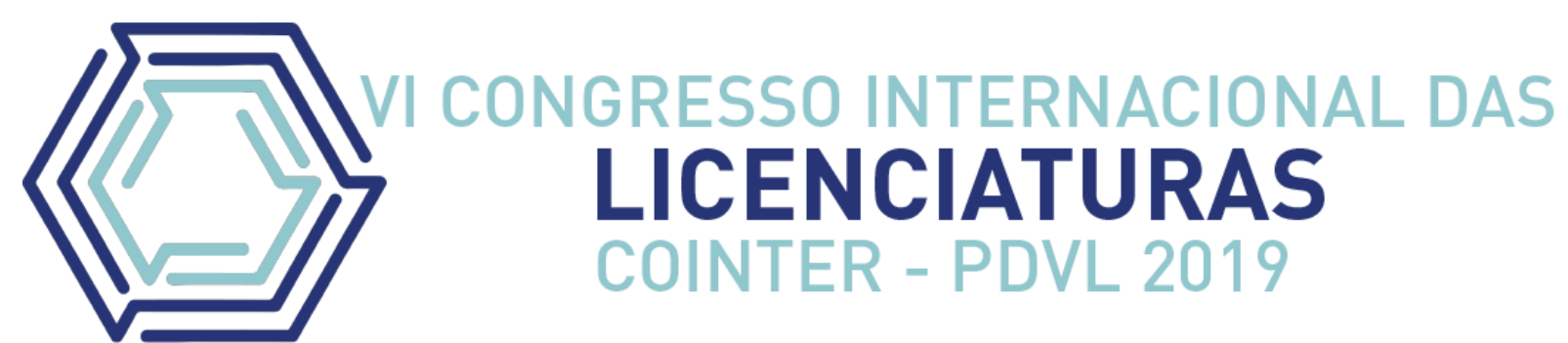

\title{
PROPOSTA DE ENSINO INTERDISCIPLINAR: ABORDAGEM DE TEMÁTICAS DIVERSIFICADAS NO CURSO DE LICENCIATURA EM QUÍMICA DO IFPB, CAMPUS JOÃO PESSOA
}

\section{PROPOSAL FOR INTERDISCIPLINARY EDUCATION: APPROACHING DIVERSIFIED THEMES IN THE IFPB CHEMICAL LICENSE COURSE, CAMPUS JOÃO PESSOA}

\section{PROPUESTA DE EDUCACIÓN INTERDISCIPLINARIA: ENFOQUE DE TEMAS DIVERSIFICADOS EN EL CURSO DE LICENCIA DE QUÍMICA IFPB, CAMPUS JOÃO PESSOA}

\author{
Apresentação: Comunicação Oral
}

Lucas Oliveira do Rosário $^{1}$; José Leonardo Alves Ferreira ${ }^{2}$; Rhayane de Oliveira Santos ${ }^{3}$; Kamilla Karoline Pereira Rodrigues ${ }^{4}$; Alessandra Marcone Tavares Alves de Figueirêdo ${ }^{5}$

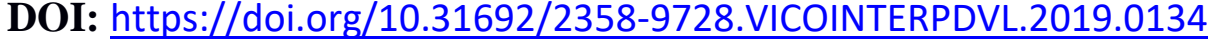

\section{Resumo}

A Química é uma disciplina que descreve os fenômenos naturais, em que em sua maioria acontece de forma microscópica, o que torna, para a maioria dos estudantes, uma área de difícil compreensão. Tal fato corrobora para uma alta abstração e subjeção dessa Ciência. Nesse sentido, buscando melhorar a aprendizagem dos discentes, faz-se necessário o uso da contextualização objetivando relacionar conteúdos químicos com a vivência deles. Sob essa perspectiva, o Programa de Educação Tutorial - PET Química do Instituto Federal da Paraíba (IFPB), Campus João Pessoa, realiza a atividade de ensino intitulada "Ciclo de Palestras", em que são abordados temas do cotidiano pouco vistos durante o período acadêmico dos licenciandos em Química, possibilitando elucidar mais a relação entre os fenômenos que ocorrem no dia a dia e a Química. As metodologias utilizadas nesse trabalho foram de cunho qualitativo e participante. A priori, foi entregue em Questionário de Sondagem (QS) no intuito de investigar os conhecimentos prévios dos estudantes sobre as temáticas que seriam abordadas nas palestras. Na sequência, foram apresentadas pelos PETianos do curso de Licenciatura em Química da supracitada instituição, duas palestras intituladas: "Chocoquímica: conhecimentos sobre a delícia misteriosa" e "Desvendando os mistérios da antimatéria" para um público de 20 (vinte) discentes. Posteriormente, foi aplicado um

\footnotetext{
${ }^{1}$ Graduando em Licenciatura em Química, IFPB Campus João Pessoa, luca.s2016@hotmail.com

${ }^{2}$ Graduando em Licenciatura em Química, IFPB Campus João Pessoa, flaleo2012@gmail.com

${ }^{3}$ Graduanda em Licenciatura em Química, IFPB Campus João Pessoa, santosrhayane.17@gmail.com

${ }^{4}$ Graduanda em Licenciatura em Química, IFPB Campus João Pessoa, rodrigues.kamilla@gmail.com

${ }^{5}$ Doutora em Química, IFPB Campus João Pessoa, alessandratavaresfigueiredo@ifpb.edu.br
} 
Questionário Final (QF) com a finalidade de observar o progresso obtido após a intervenção com apresentação das palestras. Diante dos resultados obtidos, foi possível constatar a importância que atividades como essa possui na formação de futuros professores, pois esta colaborou na construção do conhecimento dos discentes participantes, ao fomentar a compreensão desses conteúdos e incitar o estudo de temáticas não usuais, que estão além da matriz curricular do citado curso.

Palavras-Chave: Antimatéria, Chocolate, Ensino de Química, Palestras.

\title{
Resumén
}

La química es una disciplina que describe los fenómenos naturales, la mayoría de los cuales ocurren microscópicamente, lo que dificulta la comprensión de la mayoría de los estudiantes. En este sentido, buscando mejorar el aprendizaje de los estudiantes, es necesario utilizar la contextualización para poder relacionar el contenido de esta Ciencia con su experiencia. Desde esta perspectiva, el Programa de Educación Tutorial - PET Química, del Instituto Federal de Paraíba (IFPB), Campus João Pessoa, lleva a cabo la actividad docente titulada "Ciclo de conferencias", en la que se abordan temas de la vida cotidiana raramente vistos durante el período académico, lo que permite dilucidar aún más la relación entre los fenómenos cotidianos y la química. Las metodologías utilizadas en este trabajo fueron cualitativas y participativas. En este sentido, los PETianos del curso de Licenciatura en Química de la institución mencionada presentaron dos conferencias: "Chocoquímica: conocimiento sobre el deleite misterioso" y "Desentrañando los misterios de la antimateria". Por lo tanto, fue posible contribuir a la construcción del conocimiento de los estudiantes participantes, permitiendo la comprensión de estos contenidos y alentando el estudio de temas inusuales en el curso.

Palabras Clave: Antimateria, Chocolate, Enseñanza de Química, Conferencias.

\begin{abstract}
Chemistry is a discipline that describes natural phenomena, that most of which happen microscopically, which makes it difficult for most students to grasp. In this sense, to improve their learning, the use of contextualization is imperative to be able to relate this Science with their experience. From this perspective, the PET (in english, Tutorial Education Program) Chemistry of the Instituto Federal da Paraíba (IFPB), Campus Joao Pessoa, conducts the teaching activity entitled "Cycle of Lectures", in which topics of daily life rarely seen during the academic time are addressed, making it possible to further relucidate the relationship between everyday phenomena and Chemistry. The methodologies used in this work were qualitative and participatory. In this perspective, two lectures were presented by the PETians of the degree course in Chemistry of the afore mentioned institution: "Chocoquímica: knowledge about the mysterious delight" and "Unraveling the mysteries of antimatter". The refore, it was possible to contribute to the construction of the knowledge of the participating students, enabling the understanding of these contents and encouraging the study of unusual themes in the course.
\end{abstract}

Keywords: Antimatter, Chocolate, Chemistry Teaching, Lectures. 


\section{Introdução}

A abordagem de temas geradores no processo de ensino, tem sido difundida por vários pesquisadores, uma vez que possibilitam unir o conteúdo científico com os assuntos do cotidiano. Assim como há importância de relacionar a vivência dos discentes com os conhecimentos científicos, também é necessário considerar todo o conhecimento prévio que o alunado possui, pois é a partir desses conhecimentos que serão utilizados para dar sentido na compreensão e interpretação a novos conceitos, o que é denominado por Ausubel (1980) de aprendizagem significativa: "O fator isolado mais importante que influencia a aprendizagem é aquilo que o aprendiz já conhece. Descubra o que ele sabe e baseie nisso os seus ensinamentos".

Nessa perspectiva, o Programa de Educação Tutorial - PET do curso de Licenciatura em Química do Instituto Federal da Paraíba - IFPB, Campus João Pessoa, (PET Química), promoveu palestras nas quais envolviam assuntos presentes no cotidiano, possibilitando discussões, conhecimento cultural, social e científico, além de proporcionar debates entre o grupo. Dessa forma, foram ministradas duas palestras, envolvendo temáticas como a antimatéria e o chocolate. Este último foi escolhido, por ser um alimento consumido em grande escala por todas as faixas etárias, e por ser um tema envolvente, com discussões interessantes, pois pouco se sabe sobre. Desse modo, há uma grande controvérsia entre os consumidores, quanto a sua origem, os tipos de chocolates, os benefícios e a sua composição, o que causa uma grande dúvida na hora da classificação (OLIVEIRA et al, 2016).

Em concernência à antimatéria, no âmbito científico, esta destaca-se pelo fato de ser um material que possui grande valor no mercado devido a sua grande dificuldade de produção, e que pode contribuir em diversas áreas. Existem duas formas em que a antimatéria é capaz de servir como avanço na humanidade: (a) auxilia no diagnóstico de doenças; (b) é capaz de servir como combustível para foguetes, visto que é produzida uma alta quantidade de energia com pouca quantidade de antimatéria.

\section{Fundamentação Teórica}

\section{Aprendizagem Significativa}

A aprendizagem significativa é baseada na ideia de que as novas informações que 
estão sendo transmitidas para os discentes deverão ser relacionadas concomitantemente com os assuntos específicos e experiências que estes possuem, ou seja, uma forma de atrelar significados aos conteúdos. De acordo Ausubel (1978, p. 41):

\begin{abstract}
a essência do processo de aprendizagem significativa é que ideias simbolicamente expressas sejam relacionadas de maneira substantiva (não-literal) e não arbitrária ao que o aprendiz já sabe, ou seja, a algum aspecto de sua estrutura cognitiva especificamente relevante para a aprendizagem dessas ideias. Este aspecto especificamente relevante pode ser, por exemplo uma imagem, um símbolo, um conceito, uma proposição, já significativo.
\end{abstract}

Sob esse viés, além de considerar todo e qualquer conhecimento prévio existente no discente, é de fundamental importância entender a relação do cotidiano com os conceitos científicos no processo de ensino e aprendizagem, pois só assim, os novos conceitos apreendidos terão algum sentido, a partir dos conhecimentos já existentes.

\title{
Interdisciplinaridade
}

A articulação da prática pedagógica permite uma visão multifacetada do ensino, deixando de lado o tradicionalismo da visão única do conhecimento. Nessa perspectiva, segundo os Parâmetros Curriculares Nacionais + (PCN+),

\footnotetext{
A interdisciplinaridade supõe um eixo integrador, que pode ser o objeto de conhecimento, um projeto de investigação, um plano de intervenção. Nesse sentido, ela deve partir da necessidade sentida pelas escolas, professores e alunos de explicar, compreender, intervir, mudar, prever, algo que desafia uma disciplina isolada e atrai a atenção de mais de um olhar, talvez vários (BRASIL, 2002, p. 88-89, grifo do autor).
}

De acordo com Nesselo (2010), a interdisciplinaridade proporciona a interligação de, no mínimo, dois componentes curriculares, articulando os fenômenos, conteúdos e práticas de ensino. Neste sentido, em uma sociedade que supervaloriza os saberes científicos, a interdisciplinaridade se caracteriza nas propostas curriculares como um processo capaz de construir pontes entre as mais diversas áreas do conhecimento.

Em alusão à Química, por ser uma disciplina considerada abstrata, muitas das vezes o ensino torna-se fragmentado dos demais saberes científicos. Nesta perspectiva, faz-se necessário a correlação desta Ciência às demais disciplinas tornando-a mais atrativa.

Dentro dessa conjuntura, professores reunidos buscando formas de trabalhar e transmitir da melhor forma o conhecimento, intensifica e fortalece o aprendizado. Um exemplo que pode ser utilizado são os temas geradores, estes são essenciais no processo de ensino e aprendizagem, pois fogem do tradicionalismo das propostas metodológicas 
existentes, buscando trazer significados aos conteúdos da disciplina de Química atrelada com as outras áreas do conhecimento.

\section{Antimatéria}

A possível escassez de fontes de energia e a preocupação com o meio ambiente tem sido os pontos chaves para o crescimento da ciência. Atualmente, a busca constante por novos materiais que sejam eficientes e possuam um alto rendimento, tem ganhado cada vez mais espaço nas pesquisas científicas (FAROU; VICENTINI, 2011).

No início da formação do universo, logo após o Big Bang, a matéria e a antimatéria foram criadas nas mesmas proporções, de modo que cada partícula possuísse sua antipartícula. Dessa forma, a antimatéria é descrita como uma extensão da antipartícula, assim como a matéria é representada como uma extensão do conceito partícula. Todo tipo de partícula existente possui sua antipartícula correspondente, a qual possui a carga oposta. Isto é, a partícula oposta do elétron (carga negativa), é o pósitron (carga positiva), já a antipartícula do próton (carga positiva), é o antipróton (carga negativa), e a do nêutron é o antinêutron, o qual não possui carga total. Vale ressaltar que quando a matéria e a antimatéria entram em contato, ocorre o processo de aniquilação, que acaba produzindo outras partículas diferentes das iniciais (SATO, 2018a)

A antimatéria é considerada uma fonte energética altamente eficaz, sendo capaz de produzir muita energia a partir de uma quantidade pequena de combustível, no entanto, o gasto para produzi-la ainda é maior do que o consumido. Laboratorialmente, o acelerador de partículas é o meio utilizado para a produção controlada de antimatéria. Na natureza, é possível encontrar fontes desse tipo de material, a exemplo da banana, que por possuir em sua composição química isótopos radioativos de Potássio, emite um pósitron a cada 75 minutos, que é rapidamente aniquilado pela matéria predominante no universo (FAROU; VICENTINI, 2011).

\section{Chocolate}

O chocolate é um alimento rico em misticismo em sua origem. A história do chocolate iniciou-se com as civilizações maias e astecas que veneravam o Deus Quetzalcoatl, acreditando que o mesmo trouxera do paraíso as sementes de cacau para o povo e que um dia ele voltaria para a terra. Para festejar a colheita eram feitos sacrifícios humanos e ofereciam às 
vítimas uma bebida, o chocolate, que na época era chamado de "tchocolath" (HERME, 2006).

Após esse marco da história, houve mudanças até chegarmos aos diferentes tipos de chocolate que encontramos atualmente, sendo um dos produtos mais consumidos do Brasil e de todo o mundo, ingerido por diferentes públicos como crianças, adultos e idosos (CARDOSO, 2003).

O chocolate consiste em uma mistura de carboidratos (60\%), proteínas (8\%) e lipídios (30\%), além de minerais (cloro, cálcio, sódio, magnésio, ferro, cobre, zinco) e vitaminas (A, B1, B2, B3 e E). Por conta disso, o mesmo é popularmente considerado um alimento altamente energético, que traz características para os consumidores, como euforia, felicidade, possíveis benefícios para saúde, entre outros, o que se deve a sua composição química. No entanto, dentre as variadas substâncias que compõem o chocolate, as que se destacam são a cafeína, teobromina e os polifenóis.

De modo geral, os compostos químicos presentes no chocolate possuem propriedades estimulantes e antioxidantes, o que significa um efeito benéfico no corpo humano, particularmente no sistema cardiovascular e neurológico, a partir da ativação dos neurotransmissores de alguns hormônios.

\section{Metodologia}

Para o estudo dos temas propostos, foi utilizada a metodologia qualitativa, a qual "pode descrever a complexidade de determinado problema, analisar a interação de certas variáveis, compreender e classificar processos dinâmicos vividos por grupos sociais" (RICHARDSON, 1999, p. 80). Além disso, uma pesquisa participante também foi usada, em que "caracteriza-se pela interação entre os pesquisadores e os membros das situações investigadas" (SILVA e GRIGOLO, 2002 apud RAUPP e BEUREN, 2006, p. 90).

Nessa conjuntura, a atividade que teve a duração de 4 (quatro) horas, foi desenvolvida pelo grupo PET Química do IFPB, Campus João Pessoa, Paraíba, Brasil, e contou com a participação de dois bolsistas do mencionado programa para a realização da mesma. Intitulada de "Ciclo de Palestras", tal atividade tem como característica desenvolver palestras com temas geradores associados ao âmbito da Química, oportunizando debates de assuntos que, normalmente, não são discutidos durante a graduação. Nessa premissa, as palestras denominadas "Desvendando os mistérios da antimatéria" e "Chocoquímica: conhecimentos 
sobre a delícia misteriosa" foram ministradas para os discentes do curso de Licenciatura em Química do IFPB, Campus João Pessoa, totalizando um público de 20 (vinte) pessoas, pertencentes a todos os períodos $\left(1^{\circ}\right.$ ao $\left.7^{\circ}\right)$.

No primeiro momento da atividade, antes do início das apresentações, os PETianos passaram um Questionário de Sondagem (QS) para verificar os conhecimentos prévios dos licenciandos, contendo 4 (quatro) questões abertas, duas para cada palestra. Em seguida, no segundo momento, iniciaram-se as palestras. Ao término das ministrações, no terceiro momento, foi entregue um Questionário Final (QF), com o intuito de avaliar a percepção dos ouvintes acerca das temáticas abordadas, bem como, a relevância de atividades como o Ciclo de Palestras na formação docente.

\section{RESULTADOS E DISCUSSÃO}

No primeiro momento da atividade, foi distribuído para os participantes um Questionário de Sondagem com o propósito de averiguar seus conhecimentos prévios referente às palestras a serem ministradas e, dessa forma, possibilitar aos ministrantes uma breve noção sobre os saberes empíricos desse público. Conhecimentos esses, que, posteriormente, seriam explorados durante as abordagens das temáticas, favorecendo assim, a troca de saberes e a construção de novos conhecimentos por meio das diferentes perspectivas dos discentes.

Os dados evidenciados nos questionários foram analisados e se encontram descritos na sequência, identificados pela combinação entre as letras QS, maiúsculas, seguidas por um numeral correspondente a cada questionário respondido, ambos destacados em negrito.

A primeira indagação sobre a palestra "Desvendando os mistérios da Antimatéria", questionava se os discentes já se depararam com alguma informação sobre esse material e em caso afirmativo, descrevesse como ficou sabendo de sua existência. Nas respostas apuradas, percebeu-se que $50 \%$ dos estudantes relataram já terem ouvido algo sobre o material, em contrapartida, a outra metade declarou não conhecer.

O meio de contato dos discentes com antimatéria mais citado foi a internet, por meio de artigos eletrônicos, redes sociais e canais do YouTube, outro meio mencionado foi por intermédio de uma série de televisão. Todavia, foi percebido que mesmo aqueles que 
afirmaram conhecer esse material, possuíam apenas um entendimento ínfimo sobre o mesmo, ou seja, compreendiam que a antimatéria era o oposto da matéria que conhecemos (apresenta cargas invertidas), como descrito nos questionários (QS7 e QS9), respectivamente “[...] é o contrário da matéria [...]"; "Sim! A antimatéria é o material oposto a matéria”.

Esse feedback apenas reforça a importância da difusão dessa temática no meio acadêmico, em especial, nos cursos de Química, visto que, o ramo dessa ciência se caracteriza pelo estudo "da matéria e das mudanças que ela sofre" (CHANG e GOLDSBY, 2011, p. 2). Logo, a compreensão acerca dos conceitos de partículas que apresentam cargas opostas as partículas subatômicas ordinárias, agregarão aos saberes científicos dos graduandos, e, dessa forma, poderão desenvolver a capacidade de assimilar as diversas aplicações futurísticas oriundas da antimatéria (SANTOS, 2002). Como é o caso da Tomografia por Emissão de Pósitrons (PET Scam), técnica utilizada pela Física Médica para observar processos metabólicos no corpo humano de forma a auxiliar no diagnóstico de doenças (SATO, 2018b).

O segundo questionamento, ainda sobre a visão geral do assunto da supracitada palestra, requisitava que os ouvintes informassem os materiais mais valiosos existentes, conforme suas concepções. E qual a razão para tais materiais possuírem valores tão elevados.

O ouro, o rubi e o diamante, foram os materiais mais citados, numa frequência de $75 \%, 41,7 \%$ e $58,2 \%$ respectivamente, sendo assim, estes foram os materiais considerados como sendo os mais valiosos na perspectiva discente. Porém, é oportuno salientar que os alunos ainda dispõem de um pensamento equivocado, acreditando que o ouro continua sendo o elemento/material mais valioso do mundo. Entretanto, pesquisas realizadas recentemente o coloca na $11^{\text {a }}$ posição, custando 150 reais por grama. Bem mais valorizado que o ouro é o próprio diamante, custando 150 mil reais o grama e ocupando a $3^{-}$posição do ranking mundial. Já o material mais caro do mundo na atualidade, a antimatéria, objeto do nosso estudo, foi mencionado uma única vez. Sato (2018), destaca que o custo para a produção de antiprótons é de 24 trilhões de reais por grama.

A primeira questão sobre a segunda palestra "Chocoquímica: conhecimentos sobre a delícia misteriosa", fazia a seguinte indagação: "De acordo com seus conhecimentos prévios, descreva o que você conhece sobre o chocolate. (“o que é?”, benefícios, malefícios, diferenças entre os tipos, etc.)." 
Os participantes sentiram-se livres para escreverem realmente o que sabiam sobre o tema abordado. Com um rendimento máximo (100\%), não foram obtidas respostas em branco, no entanto, observou-se que algumas respostas foram mais bem elaboradas que outras, mostrando assim, a heterogeneidade dos conhecimentos prévios dos indivíduos presentes. Logo tal indagação favoreceu a percepção do olhar epistemológico sobre temática, pois foram apresentadas pelas discentes diferentes formas, cuja, temática está inserida, possibilitando a inserção da contextualização a fim de lapidar tais conhecimentos.

A segunda questão alusiva a essa segunda palestra, serviu como uma complementação, "Você saberia relacionar chocolate com a Química? Se sim, relate nas linhas abaixo". Nessa questão, cerca de $80 \%$, dos participantes conseguiram de diversas formas e em várias perspectivas mostrar a forma na qual, compreendem e/ou conhecem o tema. Em contrapartida, os outros $20 \%$ não conseguiram associar o tema com a Química, portanto, notou-se a importância da contextualização e de como ela deve ser abordada, ampliando a visão científica dos indivíduos referentes ao seu dia a dia. Corroborando assim com os PCN's:

\footnotetext{
Com essa compreensão, o aprendizado deve contribuir não só para o conhecimento técnico, mas também para uma cultura mais ampla, desenvolvendo meios para a interpretação de fatos naturais, a compreensão de procedimentos e equipamentos do cotidiano social e profissional, assim como para a articulação de uma visão do mundo natural e social. (BRASIL, 2000, p.6-7).
}

No segundo momento da atividade, procedeu-se com a ministração das palestras. A Figura 1 ilustra a primeira palestra sobre a antimatéria em que foram abordados os tópicos arrolados: contexto histórico da antimatéria, sua classificação, efeitos da interação matériaantimatéria, sintetização, armazenamento, formas de produção natural, aplicações na física médica e assimetria matéria- antimatéria. 
Figura 1: Palestra: "Desvendando os mistérios da Antimatéria”.

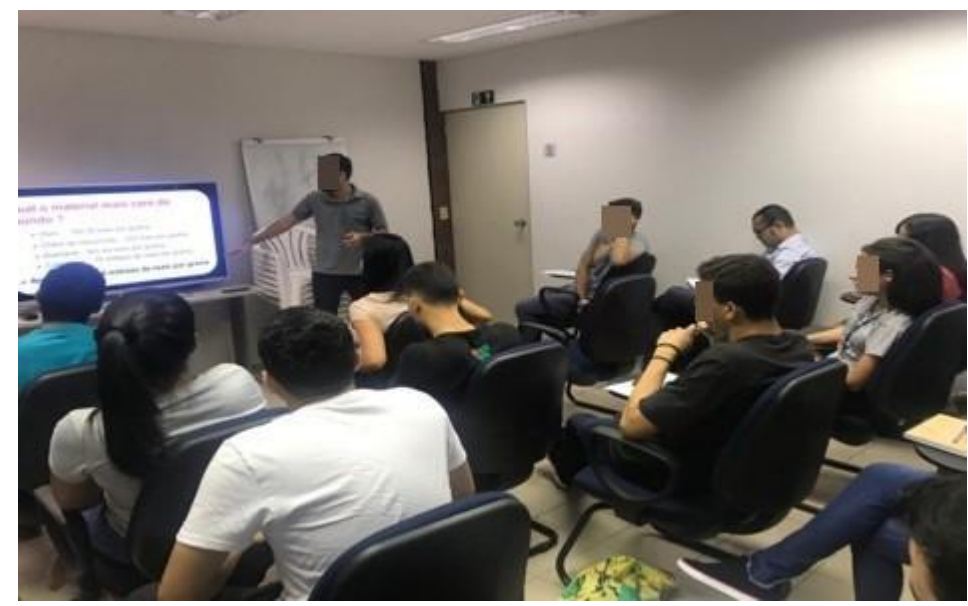

Fonte: Própria (2019)

A priori, optou-se por iniciar a abordagem sobre a Antimatéria com os dois questionamentos requisitados no QS, conceito da Antimatéria e preciosidade dos materiais da atualidade, com o intuito de estimular a participação dos educandos e promover um momento rico de aprendizagem por meio de debates reflexivos, além da troca de conhecimento entre o público presente, dado que, todos os envolvidos nesse ambiente de aprendizagem são graduandos pertencentes aos diversos períodos do curso de Licenciatura em Química.

Desta forma, o debate torna-se uma estratégia de ensino e aprendizagem essencial para a aquisição de conhecimentos, pois, essa dinâmica de ensino corrobora para que discentes de períodos mais avançados do curso possam contribuir cognitivamente com a formação daqueles que se encontram em períodos iniciais e vice-versa. Nessa conjectura, Freire (1996, p. 23) descreve que, "quem ensina aprende ao ensinar e quem aprende ensina ao aprender". Destacando-se nessa relação à dimensão afetiva.

Durante a explanação da palestra, alguns tópicos em específicos foram motivos de maiores discussões entre os discentes, dentre eles, destaca-se a informação de que pequenas quantidades de antimatéria podem existir de maneira natural. Por exemplo, em média uma banana emite um pósitron $\mathrm{e}^{+}$(elétron de carga positiva) a cada 75 minutos, isto acontece devido a sua composição química existir um isótopo de potássio $\left({ }^{40} \mathrm{~K}\right)$ que sofre decaimento $\beta+$, ocasionado pela transformação de um próton em um nêutron que resulta na emissão de um pósitron mais um neutrino (SATO, 2018; OSTERMANN e CAVALCANTI, 2001). Entretanto, como o universo é constituído predominantemente de matéria, instantaneamente esse pósitron colide com um elétron e ambos se aniquilam, restando apenas radiação. 
Outro ponto de destaque foi, concernente ao princípio de funcionamento do PET Scam, que consiste na utilização de radiofármacos, como o Fluordesoglicose (FDG), substância semelhante a glicose comum, mas que contém um dos átomos de oxigênios substituído por um radioisótopo de flúor $\left({ }^{18} \mathrm{~F}\right)$, como ilustrado na Figura 2. Quando essa substância é introduzida, o corpo a reconhece como glicose e a transporta para as células que precisam de glicose, porém, a ausência do átomo de oxigênio impossibilita a metabolização da molécula, fazendo com que ocorra o decaimento $\beta+$ do $\left({ }^{18} \mathrm{~F}\right)$. Dessa maneira, se existirem células cancerígenas, que consomem a glicose como fonte de energia para continuarem se dividindo, o equipamento detectará uma maior emissão de fótons em determinada região (SATO, 2018; PEREIRA, PEREIRA e ZOTES, 2016).

Figura 2: Molécula de Fluordesoglicose.

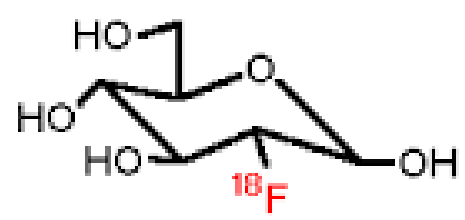

Fonte: Pereira, Pereira e Zotes (2016).

Nesse contexto, um ouvinte fez uma excelente indagação, ele questionou se essa elevada emissão de fótons, resultante da aniquilação entre o pósitron e o elétron, poderia, de alguma forma, prejudicar a integridade física do paciente, visto que, a colisão entre matériaantimatéria converte toda a massa de suas partículas em pura energia (BEDIAGA, 2010). E assertivamente, uma segunda ouvinte respondeu que talvez esse risco não existisse, devido a massa do elétron ser extremamente pequena.

Em menção a palestra "Chocoquímica: conhecimentos sobre a delícia misteriosa" (Figura 3), também houve a explanação de tópicos referentes ao contexto histórico desse produto e, posteriormente, perpassando pelos processos químicos de produção, os diferentes tipos do doce, sua composição referente aos seus minerais e as substâncias ativas presentes. Além disso, foram explicadas questões sobre os benefícios e malefícios causados pelo chocolate à saúde corporal. 
Figura 3: Palestra: "Chocoquímica: conhecimentos sobre a delícia misteriosa".

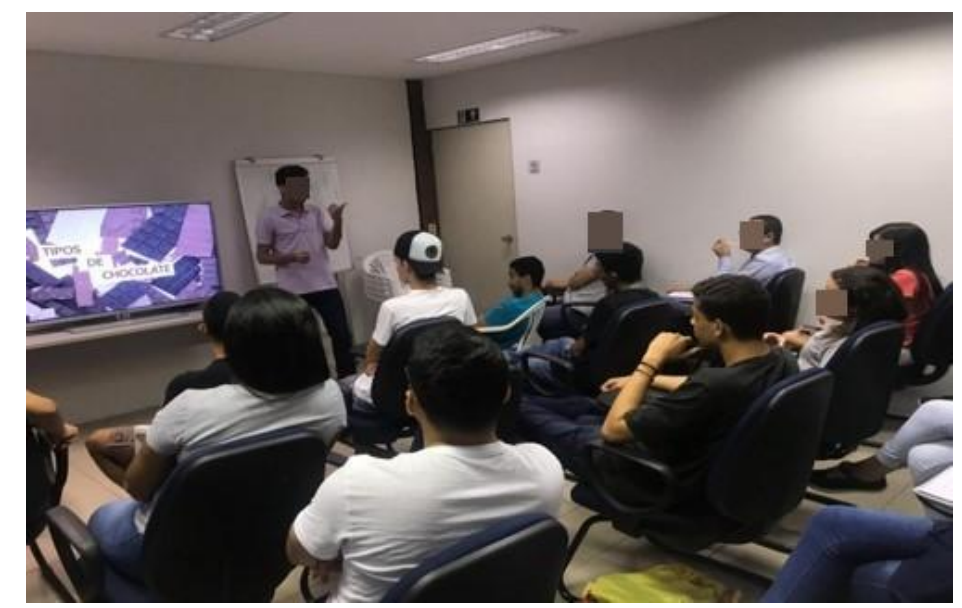

Fonte: Própria (2019)

Segundo D'el-Rei e Medeiros o chocolate

[...] apesar de ser um alimento que vem despertando interesse científico pôr seu efeito na pressão arterial e na saúde cardiovascular de um modo geral, seu consumo deve ser recomendado com cautela, pois além de veicular os flavonóides, responsáveis por seus efeitos benéficos, também veicula uma grande quantidade de energia, o que poderia contribuir para o ganho de peso (2011, p. 58).

O envolvimento com a Química cerebral também foi abordado, citando as relações entre o chocolate, os aminoácidos, as enzimas e a importância desses nas mudanças de humor. No decorrer das apresentações, alguns questionamentos foram suscitados, assim, ocasionando momentos enriquecedores de debates, trocas de informações e construção de novos conhecimentos.

Nessa perspectiva, os Parâmetros Curriculares Nacionais para o Ensino Médio (PCNs) atestam para importância de estimular a interação entre aluno-aluno e aluno-mediador, pois momentos como estes favorecem o desenvolvimento de competências cognitivas superiores, além de, propiciar formas coletivas de conhecimento (BRASIL, 2000).

Para o fechamento da segunda palestra, foi promovido um momento dinâmico utilizando um "Quiz" como recurso auxiliador para revisar o conteúdo apresentado e incentivar o diálogo com os ouvintes, visto que, conforme atenta Freire,

[...], o diálogo é uma exigência existencial. E, se ele é o encontro em que se solidarizam o refletir e o agir de seus sujeitos endereçados ao mundo a ser transformado e humanizado, não pode reduzir-se a um ato de depositar ideias de um sujeito no outro, nem tampouco tornar-se simples troca de ideias a serem consumidas pelos permutantes. (2005, p. 91). 
O momento foi propício, pois gerou debates, facilitou a interação com a turma, que por sua vez, aderiu a ideia, já que serviu como uma "quebra" da palestra expositiva e deu-lhes o direito de falar mais abertamente, tirar dúvidas e por fim responder às perguntas do "Quiz", exercitando e revisando o conteúdo trabalhado.

Ao término das palestras, foi entregue aos licenciandos um Questionário Final contendo duas inquirições concernentes a cada palestra. A identificação desses questionários foi feita pela junção entre as letras QF, maiúsculas, seguidas por um numeral, todos destacados em negrito, correspondente a cada questionário respondido.

Em alusão ao primeiro questionamento do QF referente a exposição sobre a Antimatéria: Conforme o explanado na palestra e considerando sua perspectiva como docente em formação, explique como os conhecimentos adquiridos poderiam agregar em suas aulas de Química. E se esse conteúdo seria favorável para instigar os discentes a ter uma visão mais positiva desta disciplina?

Nos dados coletados, verificou-se que todos os graduandos participantes acreditam que a referida temática trouxe contribuições significativas acerca de seu desenvolvimento como docente em formação, em virtude da relevância que essas discussões abrangem o atual cenário tecnológico. Assim como, as inúmeras possibilidades de promover um ensino de Química contextualizado e interdisciplinar com um tema infimamente discutido no curso de Licenciatura em Química, mas de grande relevância no âmbito acadêmico. Tais argumentos podem ser constatados no QF3: “A antimatéria influencia em conhecimentos para além do espaço e procedimentos médicos de imagem, atrelados a conhecimentos físicos. Essa temática pode facilitar a forma que os estudantes veem a Química e sua utilidade na sociedade atual”.

Outra resposta relevante foi verificada no QF12: “É importante, pois um docente de Química deve saber todas as coisas que englobam a matéria e esse é um assunto muito interessante que chamaria a atenção dos alunos e facilitaria o entendimento e a vontade de aprender mais sobre a matéria e a antimatéria”. Esses pensamentos corroboram com o fato de que no ensino superior existe uma ausência de correlação entre o conteúdo disciplinar e a realidade dos discentes. Os professores, na tentativa de fazer seus estudantes a aprender, o fazem de maneira equivocada, dando mais importância ao conteúdo em si, ao invés de 
explorar a interligação com a qual a situação emerge, resultando, assim, na clássica dicotomia entre teoria e prática (FAVARÃO e ARAÚJO, 2004).

Ainda em conformidade com os argumentos desses autores, observa-se a importância de recorrer a estratégias pedagógicas de ensino, como a contextualização e a interdisciplinaridade, para a difusão de um processo educacional mais significativo:

A educação deve ser entendida e trabalhada de forma interdisciplinar, na qual o aluno é agente ativo, comprometido, responsável, capaz de planejar suas ações, assumir responsabilidades, tomar atitudes diante dos fatos e interagir no meio em que vive contribuindo, desta forma, para a melhoria do processo de ensino e aprendizagem. [...] Nessa perspectiva, para que o mesmo adquira essas habilidades, faz-se necessário trabalhar com práticas pedagógicas voltadas para a formação do aluno, para o exercício da cidadania plena, respeitando a individualidade de cada um, utilizando-se de conteúdos interdisciplinares e contextualizados (FAVARÃO e ARAÚJO, 2004, p. 104).

A segunda interpelação foi elaborada em virtude das consequências benéficas e/ou maléficas que o domínio da produção de antimatéria poderia acarretar para a sociedade. Para tanto, perguntou-se a opinião dos discentes a respeito desta dubiedade.

Cerca de 66,7 \% dos discentes apresentaram certa indecisão sobre este questionamento. Como averiguado no QF12: "Sim, é algo difícil de se prever, pois como várias outras tecnologias revolucionárias foram usadas tanto em aplicações benéficas quanto maléficas [...] sua aplicação dependerá apenas da nossa educação futuramente”.

Esta indecisão é, de certa forma, compreensível, devido a vasta gama de possibilidades que esse material pode ser destinado, seja sua utilização em prol da humanidade, como na área medicinal, ou na produção de combustível como fonte de energia para possibilitar a exploração espacial por aeronaves, dentre outros (SATO, 2018). Todavia, também podem ser destinadas para o desenvolvimento de bombas mais poderosas que as ogivas nucleares, posto que, a aniquilação dos pares (matéria e antimatéria) é o único processo que converte $100 \%$ da massa das partículas em energia (SATO, 2018; NOGUEIRA, 2016).

Referente a segunda palestra: "Chocoquímica: conhecimentos sobre a delícia misteriosa", como primeira questão do QF foram abordados os conhecimentos teóricos sobre os conteúdos químicos apresentados. Questão 1 (um): “Cite as diferenças na composição química dos diferentes tipos de chocolates abordados na palestra”. 
Para essa questão, foi obtida uma diversidade de respostas, mostrando assim a heterogeneidade do grupo, com respostas mais completas que outras. A fim de exemplificar o que foi dito, destacam-se duas respostas dos discentes:

QF9: “Os chocolates podem ser diferenciados na sua composição química, através de sua composição, pois alguns é mais escuro, pois tem polifenóis, outro é mais branco, porque tem mais gordura e leite”.

QF6: "Chocolate amargo tem mais teor de cacau, sendo $80 \%$. Passando pela oxidação e cordão aromático e fermentação produzindo polifenóis. Já o chocolate ao leite contém pouco mais de $20 \%$ de cacau e bastante complementado com componentes sólidos; leite em pó e etc. O chocolate branco contém mais manteiga de cacau, e gordura”.

Dado o exposto e tendo em vista as respostas dos discentes, podemos confirmar que eles conseguiram assimilar de forma positiva o que foi ministrado.

O segundo questionamento concernia à aplicação dos conteúdos absorvidos pelos mesmos e também à importância e contribuição que a temática trouxe para suas vidas acadêmicas como licenciandos em Química. Questão 2 (dois): “Comente como a palestra "Chocoquímica: conhecimentos sobre a delícia misteriosa" contribuiu com seus conhecimentos químicos sobre o chocolate e, como esta foi importante para você como licenciando em Química". Aproximadamente $70 \%$ dos participantes conseguiram responder adequadamente o questionamento, detalhando com precisão a necessidade e a contribuição de tal temática no âmbito estudantil, já os outros $30 \%$ não foram muito objetivos na assimilação da proposta. Alguns relatos dos respondentes estão elencados:

QF6: "Planejamento da aula, o uso de elementos químicos a importância da serotonina e dopamina, a importância de consumir alimentos, hábitos que estimulam essas substancias no nosso organismo.

QF3: “Ampliou o conhecimento a respeito dos seus prós e contras de acordo com o tipo de chocolate, a quantidade de cacau, quanto mais dopamina e serotonina irão ser produzidas no cérebro. Com isso adquirido, mais fácil será de ensinar aos alunos, certos assuntos químicos, sempre levando coisas corriqueiras atreladas ao ensino da química para melhorar a didática e conhecimento passado." 
No que tange ao Questionário Final, diante das respostas dos graduandos em Química, foi possível averiguar que este instrumento avaliativo serviu para consolidar conteúdos, muitas vezes, não explorados ao longo do curso.

Por fim, é importante ressalvar o envolvimento dos estudantes com as discussões, originadas a partir da abordagem dos dois temas. Dessa maneira, tais discussões foram etapas fundamentais no desenvolvimento das apresentações, proporcionando aos participantes, uma carga mais diversificada de conhecimentos que, como mencionado por alguns discentes, forneceram informações essenciais, no tocante à construção de novos conhecimentos.

\section{CONCLUSÕES}

Por meio da interação dos discentes durante a execução da atividade, foi possível constatar a importância que um "Ciclo de Palestras" possui na formação desses futuros profissionais. Dado que, é primordial que os professores sejam detentores de conhecimentos que transcendam àqueles exigidos pelas ementas dos Cursos de Licenciatura. Para que, dessa forma, discorra um processo de ensino-aprendizagem contextualizado e interdisciplinar, com temáticas interessantes, diversificadas e atuais.

Destarte, é indispensável que informações como estas sejam disseminadas no ambiente acadêmico, em virtude da relação que estas possuem com o cotidiano, e por serem temáticas que estão além da matriz curricular do curso de Licenciatura em Química.

\section{Referências}

AUSUBEL, David P., NOVAK, Joseph D., HANESIAN, Helen. Psicologia educacional. Tradução Eva Nick. Rio de Janeiro: Interamericana, 1980.

AUSUBEL, D. P., NOVAK, J.D. and HANESIAN, H. Educationalpsychology: a cognitiveview. (2 ed) Nova York, Holt, Rinehart and Winston, 1978.

BEDIAGA, I. A. Antimatéria e o Universo. Ciência Hoje, v. 45, n. 268, 2010. Disponível: http://lhcb-public.web.cern.ch/lhcb-public/en/lhcb-

outreach/documentation/ArtigoAntimateria.pdf. Acesso em: 11/09/2019.

BRASIL. Parâmetro Curriculares Nacionais para o Ensino Médio. Secretaria de Educação Básica. - Brasília: Ministério da Educação, Secretaria de Educação Básica, 2000.

BRASIL. Ministério da Educação. Secretaria de Educação Média e Tecnológica. Parâmetros 
Curriculares Nacionais: Ensino Médio. Brasília: Ministério da Educação, 2002.

CARDOSO, Vanessa. Conteúdo de flúor em diversas marcas de chocolate e bolachas de chocolate encontradas no Brasil. Revista PesquiOdontol Brás. São Paulo, v.6 n 12, p 25- 29, fev.2003.

D'El-REI, J.; MEDEIROS, F. Chocolate e os benefícios cardiovasculares. Revista do Hospital Universitário Pedro Ernesto, 2011.

FAROU, M. H. E.; VICENTINI, E. Ensino de Física: o futuro da energia - A antimatéria. UNICENTRO-CEDETEG, Departamento de Física, 2011. Disponível em: https://sites.unicentro.br/wp/petfisica/files/2011/08/Antimateria_Mahmud.pdf. Acesso em: 11/09/2019.

FAVARÃO, N. R. L.; ARAÚJO, C. S. A. Importância da interdisciplinaridade no Ensino Superior. EDURECE. Umuarama, v. 4, n. 2, p. 103-115, jul./dez., 2004. Disponível em: http://www.scielo.br/scielo.php?script=sci_nlinks\&pid=S14143283201400020033700036\&lng=en. Acesso em: 13/09/2019.

FREIRE, Paulo. Pedagogia da autonomia: saberes necessários a prática educativa (Coleção Leitura). São Paulo: Paz e Terra. 1996.

FREIRE, Paulo. Pedagogia do Oprimido. Rio de Janeiro: Paz e Terra, 2005, 42. ${ }^{\text {a }}$ Edição.

HERME, Pierre. Larousse do Chocolate. Editora Larousse. $1^{\circ}$ edição São Paulo- 2006

NESELLO, Leocir José. A experimentação como possibilidade de contemplar a interdisciplinaridade. 2010. 125 f. Dissertação (Mestrado Profissional em Ensino de Ciências Exatas) - Centro Universitário UNIVATES, Lajeado, 2010.

NOGUEIRA, S. Antimatéria. Super Interessante, 2016. Disponível em: https://super.abril.com.br/ciencia/antimateria/. Acesso em: 13/09/2019.

OLIVEIRA, L. R et al. Chocoquímica: construindo conhecimentos acerca do chocolate por meio do método de aprendizagem cooperativa Jigsaw. Química nova na escola, São Paulo-SP, vol. 39, n. 3, p. 277-285, Agosto 2016. Disponível em:<http://qnesc.sbq.org.br/online/qnesc39_3/09-RSA-41-16.pdf> Acesso em: 26/04/2019.

OSTERMANN, F.; CAVALCANTI, C. J. H. Um pôster para ensinar Física de Partículas Nuclear. Revista Física na escola, v. 2, n. 1, 2001. Disponível em: https://webcache.googleusercontent.com/search?q=cache:xLKklWcassIJ:https://lume.ufrgs.br /handle/10183/116427+\&cd=1\&hl=pt-BR\&ct=clnk\&gl=br\&client=firefox-b-d. Acesso em: 11/09/2019.

PEREIRA, V. S.; PEREIRA, M. E. C.; ZOTES, L. P. A indústria de radiofármacos no Brasil: o caso da Fluordesoglicose (FDG). In: Congresso Nacional de Excelência em Gestão, 12., 2016, Rio de Janeiro. Anais... Rio de Janeiro: INOVARSE: 2016. Disponível em: http://www.inovarse.org/sites/default/files/T16_202.pdf. Acesso em: 13/09/2019.

RAUPP, F. M; BEUREN, I. M. Metodologia da Pesquisa Aplicável às Ciências. Como 
elaborar trabalhos monográficos em contabilidade: teoria e prática. São Paulo: Atlas, 2006.

RICHARDSON, R. J. Pesquisa social: métodos e técnicas. 3. ed. São Paulo: Atlas, 1999.

SANTOS, A. C. F. Interação Matéria-Antimatéria e Matéria-Matéria a Energias Intermediárias. Revista Physica e, Department of Physics, University of Missouri - Rolla, Rolla MO 65409 USA, 2002. Disponível em: < https://physicae.ifi.unicamp.br/index.php/physicae/article/view/physicae.3.5/69 >. Acesso em: 23/04/2019.

SATO, E. A. Antimatéria: o material mais caro do mundo! Blogs de Ciência da Universidade Estadual de Campinas, v. 4, n. 6, 2018a. Disponível em:https://www.blogs.unicamp.br/tortaprimordial/antimateria-o-material-mais-caro-domundo/. Acesso em: 10/09/2019.

SATO, E. A. Antimatéria (parte 2): PET Scam e assimetria matéria-antimatéria. Blogs de Ciência da Universidade Estadual de Campinas, v. 4, n. 7, 2018b. Disponível em: https://www.blogs.unicamp.br/tortaprimordial/antimateria-parte-2/. Acesso em: 23/04/2019. 